Research article

\title{
Antecedents of environmental management system internalization: Assessing managerial interpretations and cognitive framings of sustainability issues
}

\author{
Niccolò Maria Todaro*, Francesco Testa, Tiberio Daddi, Fabio Iraldo \\ Institute of Management, Sant'Anna School of Advanced Studies, Piazza Martiri della Libertà, 33 - 56127, Pisa, Italy
}

\section{A R T I C L E I N F O}

\section{Keywords:}

Environmental management system

Substantive internalization

ISO 14001

EMAS

\begin{abstract}
A B S T R A C T
Drawing on Bansal \& Roth's model of ecological responsiveness, the study investigates how environmental managers' cognitive framings of sustainability issues and interpretations of field-level contextual factors affect decision-making processes with regard to environmental management system (EMS) internalization. Using data from a survey questionnaire of 457 ISO 14001-certified and EMAS-registered European companies, the research analyses the influence of managers' perceptions of contextual factors (i.e. environmental issue salience and governmental regulatory incentives) and managers' cognitive traits (i.e. managers' environmental concern and cognitive framings of environmental practices) on internalization. The results highlight that, while managers' perceived stakeholders' concern for the natural environment directly influences substantive internalization, governmental regulatory reliefs fail to influence the internalization of EMS. Similarly, managers' environmental concern emerges as an antecedent of internalization, while managers' adherence to an alignment logic between economic and environmental objectives does not contribute to internalization. Furthermore, the study contributes to the conceptualization of substantive internalization of environmental practices, by highlighting the existence of two distinct dimensions of EMS internalization, i.e. operational and strategic internalization.
\end{abstract}

\section{Introduction}

The last decades have witnessed a rapid increase in the diffusion of certifiable environmental management systems (EMS) in most industry sectors. Since their inception in the 1990s, EN ISO 14001 and the Eco Management and Audit Scheme (EMAS) has emerged as the most widely adopted standards for integrating environmental protection policies according to internationally recognised and verifiable guidelines (Morrow and Rondinelli, 2002).

Motivations and outcomes of standard-based EMS adoption have attracted considerable interest in management research (Stevens et al., 2012; Boiral et al., 2018; Salim et al., 2018; Álvarez-García et al., 2018). Studies have demonstrated that certified EMS adoption contributes enhancing corporate legitimacy and reputation in the eyes of external stakeholders, by signalling superior environmental commitment, reliability and transparency (Bansal and Hunter, 2003; King and Bruner, 2000; Darnall, 2006; Tambovceva and Geipele, 2011; D'Souza et al., 2019). Similarly, EMS have been praised to enhance companies' business performance and competitive positioning, when coupled with significant improvements in environmental performance (Darnall et al.,
2008; Iraldo et al., 2009; Daddi et al., 2011). However, research has often provided inconclusive results concerning the relation between certified EMS adoption and better environmental performance or more effective environmental practices (Nawrocka and Parker, 2009; HerasSaizarbitoria et al., 2015; Zobel, 2016a,b; Merli \& Preziosi, 2018; Poltronieri et al., 2019).

Several scholars have indeed underlined that the mere adoption of a standard-based EMS does not necessarily improve environmental performance, as organizations may settle for a superficial or symbolic implementation of the EMS to secure benefits in terms of external legitimacy and reputation (Boiral et al., 2018; Darnall et al., 2008; Testa et al., 2014). The adoption of a certifiable EMS for mere reputational purposes correspond to "symbolic corporate environmentalism", in case environmental certification is not coupled with the material improvement of environmental performance or more effective environmental management (Bowen, 2014).

Because EMS adoption is not a sufficient condition for improving environmental performance, research on EMS has progressed to investigate the substantive internalization of EMS (Wijen, 2014). According to Christmann and Taylor (2006), internalization of a standard-

\footnotetext{
${ }^{*}$ Corresponding author.

E-mail addresses: nic.todaro@santannapisa.it (N.M. Todaro), f.testa@sssup.it (F. Testa), tiberio.daddi@sssup.it (T. Daddi), f.iraldo@sssup.it (F. Iraldo).
} 
based management system occurs when its requirements are fully coupled within the organization's daily practices. Empirical studies have indeed claimed that the substantive internalization of the EMS, as opposed to a symbolic or "ritual" adoption of the standard, leads to better environmental performance (Boiral et al., 2018; Yin and Schmeidler, 2009; Qi et al., 2012). For instance, Iraldo et al. (2009) and Testa et al. (2014) advanced that certifiable EMS, such as ISO 14001 and EMAS, leads to visible environmental improvements only when its prescriptions have been fully internalized in the daily management practices of the organization or, in other terms, when the implementation of the EMS has reached "maturity".

From understanding EMS adoption as an isomorphic response to institutional pressures, studies progressed to theorize that organizational decision-makers differ in the way they translate pressures into practice, ranging from a superficial or symbolic adoption of the EMS to a substantive implementation beyond the mere compliance with its formal requirements (Boiral et al., 2018). Similar studies define symbolic or substantive adoption of certifiable EMS as divergent strategic responses to heterogeneous, and sometimes conflicting, stakeholders' demands and institutional pressures (Christmann and Taylor, 2006; Testa et al., 2018a,b; Iatridis and Kesidou, 2018).

However, such studies fail to examine the contextual factors that lead organizational decision-makers to embrace pressures for substantive internalization, and resist pressures for symbolic adoption. Internal and external contextual conditions influence the propensity of managers to attend to specific prescriptions for adopting environmental practices, while ignoring other potential motivations (Bansal and Roth, 2000; Hoffman, 2001; Delmas and Toffel, 2004). Similar contextual antecedents may include pre-existing management practices (Yin and Schmeidler, 2009), corporate strategic orientations (Darnall et al., 2008; Testa et al., 2015), the superior commitment of organizational members (Boiral et al., 2018; Darnall et al., 2008), and clients' concern for environmental issues (Christmann and Taylor, 2006).

Despite such limited insights, contextual determinants of EMS internalization remains understudied. By focusing on the institutional dynamics underlying management system internalization, empirical research has largely overlooked the role of managers' cognitive traits and interpretations of contextual factors that affect organizational decision-making processes with regard to environmental management issues (Hoffman, 2001; Bansal, 2003). However, according to theories of micro-foundations of corporate responsibility (Gond et al., 2017), managers' sense-making and interpretation processes largely influence organizational decision-making with regard to sustainability issues (Strauss et al., 2017).

The present study contributes to this debate by exploring the relation between contextual conditions and EMS internalization, by specifically investigating how managers' cognitive framings and interpretations of contextual factors affect decision-making with regard to EMS internalization. Accordingly, drawing on data from 457 ISO 14001certified and EMAS-registered companies, the study develops and tests a comprehensive model of EMS internalization, accounting for both managers' perceptions of field-level contextual factors and managerial interpretations of environmental and sustainability issues.

Furthermore, the study contributes advancing the understanding of management system internalization, by adopting a more comprehensive measure of EMS internalization compared to previous studies. Drawing on the recent developments of the ISO 14001:2015 requirements concerning the relevance of organizational leadership and suppliers engagement (Da Fonseca, 2015), the study differentiates between the strategic aspects and operational aspects of EMS internalization. On the one hand, operational internalization denotes the extent to which companies internalize specific requirements, such as engaging suppliers and contractors in the environmental policy. On the other hand, strategic EMS internalization reflects the extent to which the top management actively takes part in designing and executing the EMS. This distinction aims at recognising that diverse approaches to EMS internalization exist, revealing further heterogeneity in companies' adoption of EMS.

Theoretically, the research bases on the model of corporate ecological responsiveness developed by Bansal and Roth (2000). The model of ecological responsiveness indeed provides a multi-level perspective on the motivations underlying proactive environmental strategies, merging intuitions from neo-institutional theory and cognitive theories, emphasizing the role of the contextual dimension (internal and external) in influencing companies' interpretation of salient issues.

\section{Theoretical framework and hypothesis development}

The debate on the internalization of proactive environmental practices envisions the substantive internalization and the symbolic adoption of certifiable EMS as divergent strategic responses to heterogeneous institutional demands (Christmann and Taylor, 2006). Building on such premises, scholars have largely applied the neo-institutional perspective to the study of motivations for EMS adoption, with the aim to identify institutional pressures, or specific stakeholders, that stimulate the substantive internalization of EMS (Castka and Prajogo, 2013; Testa et al., 2015).

For instance, according to Castka and Prajogo (2013), secondary stakeholders' pressures for EMS adoption fail to influence EMS internalization, implying that the pursuit for legitimacy in the eyes of such external constituents (such as social groups, governmental entities, NGOs or the media) does not constitute a motivation for EMS internalization. Similarly, Testa et al., 2018a,b analysed the role of diverse stakeholders' pressures in influencing the substantive or symbolic adoption of certified EMS. According to the authors, while shareholders, suppliers and financial institutions positively influence EMS internalization, pressures from clients and trade associations lead to a symbolic adoption.

However, according to Bansal and Roth (2000) model of ecological responsiveness, perceived contextual conditions and managerial interpretations are not neutral, but rather constitute an influential factor in the decision-making process underlying organizational responses to institutional pressures (Buyesse \& Verbeke, 2003; Delmas and Toffel, 2008). By providing context to the array of prescriptions to which organizations are exposed, contextual factors influence decision makers' sense-making process, affecting the interpretation of strategically salient issues (Dutton \& Jackson, 1987; Weick, 1995). Field-level and organizational contextual conditions contribute determining prescriptions or pressures that decision-makers pay attention to, and eventually contribute legitimizing organizational responses to such pressures (Dutton \& Jackson, 1987).

Investigating motivations of EMS internalization without considering the contingent conditions that legitimate and support said motivations is likely to provide only a partial understanding of the institutional dynamics underlying EMS internalization. This study posits that both exogenous and endogenous contextual factors may encourage, or discourage, managers to embrace EMS internalization as an organizational response to institutional pressures for environmental responsibility.

Endogenous and exogenous factors shape the contextual conditions in which organizational decision-makers take decisions with regard to salient environmental issues. On the one hand, exogenous factors pertain to the ecological context in which companies operate, and concern the extent to which external constituents (such as local communities, customers and local government) value, monitor or ascribe emotional importance to companies' most tangible environmental aspects (Christmann and Taylor, 2006). On the other hand, endogenous factors pertain to the organizational or individual sphere, and concern the extent to which organizational constituents value the environment, interpret environmental issues as strategically salient for the business and possess discretion, in terms of responsibility and resources, to initiate an organizational response (Aragón-Correa et al., 2004). 


\subsection{Exogenous contextual factors}

In describing most relevant contextual determinants of corporate ecological responsiveness, Bansal and Roth (2000) point out that environmental aspects that are easily observable, measurable and emotionally-charged are more likely to raise concerns from external constituents, such as local communities and governmental agencies. The authors define such environmental issues as salient, being likely to attract stakeholders' attention and damage companies' profitability due to fines or reputational backlashes. Accordingly, the extent to which local external constituents are concerned for environmental issues contributes determining a contextual condition that encourage a proactive and responsible stance on environmental issues (Bansal and Roth, 2000).

The salience that stakeholders attribute to environmental issues provides a legitimizing context for corporate environmental proactivity, incentivizing initiatives motivated by environmental improvement and competitive advantage (Bansal, 2003; Christmann and Taylor, 2006). At this regard, Christmann and Taylor (2006) claim that the extent to which primary stakeholders ascribe importance to environmental issues set the conditions for the substantive internalization of the EMS. According to the authors, decision-makers opt for a superficial implementation of the EMS when external stakeholders are merely concerned with the symbolic value of certification for legitimacy purposes. Under such circumstances, companies lack incentives to further EMS implementation beyond the minimal requirements for certification. On the other hand, companies may opt for substantively internalizing the EMS when external stakeholders place considerable importance on actual environmental performance, therefore incentivizing investments in internalization beyond mere compliance to the standard's requirements (Christmann and Taylor, 2006). Based on such observations, we formulate the following hypothesis:

Hypothesis 1. Environmental issue salience positively influences EMS internalization, both operational and strategic.

Public authorities and environmental agencies have a crucial role in influencing corporate environmental behaviour, due to their regulatory, control and enforcement powers. However, the role of public authorities in affecting companies' environmental performance extends beyond exerting coercive pressures by means of direct "command and control" regulation (Demirel et al., 2018).

Public authorities can create favourable conditions for adopting proactive environmental practices by means of diverse forms of rewarding or incentivizing mechanisms, such as regulatory reliefs or administrative benefits (Testa et al., 2016). Said regulatory initiatives aim at directly or indirectly incentivizing environmental practices by reducing barriers to their adoption, or by enhancing benefits of adoption (Glachant et al., 2002). Most commonly, public incentives focus on granting regulatory reliefs aimed at simplifying legislative procedures or reducing regulatory obligations to EMS implementers (Gouldson et al., 2009; Daddi et al., 2016).

Despite several studies have demonstrated the effectiveness of regulatory reliefs and administrative benefits in driving EMS adoption (Wätzold et al., 2011; Daddi et al., 2016; Testa et al., 2016), the influence of these regulatory incentives on managers' decision-making processes with regard to EMS internalization is understudied. Governmental regulatory incentives constitute stimuli aimed at attracting decision-makers' attention towards certifiable voluntary standards. However, decision-makers' appreciation of specific regulatory incentives may considerably vary, based on the typology or magnitude of the benefit granted and on companies' characteristics (such as size, activity, location etc.) (Daddi et al., 2016). Despite regulatory incentives are widely adopted for increasing managers' attention on certifiable EMS in most European Union Member States (Glachant et al., 2002), their effectiveness in incentivizing the substantive internalization of environmental practices remains underexplored. Accordingly, we formulate the following hypothesis:

Hypothesis 2. Regulatory incentives positively influence EMS internalization, both operational and strategic.

\subsection{Endogenous contextual factors}

Research on company's choices of environmental strategy has often delved into the organizational and managerial contextual conditions that influence decision-making with regard to corporate sustainability issues (Cordano \& Frieze, 2000). Noteworthy studies have analysed the outcomes of managerial sense-making and interpretation of environmental issues as a determinant of companies' choices of environmental strategy (Sharma and Good, 2013; Sharma, 2000; Bansal, 2003). Similar studies base on the assumption that managers' cognitive predispositions influence the selection of events or information that managers pay attention to, and the way such events or information are interpreted to inform decision-making and, eventually, organizational action (Weick, 1979; Dutton \& Jackson, 1987; Jackson and Dutton, 1988).

In line with the assumption of bounded rationality, individuals depend on their personal values and attitudes for discerning the most salient issues among the vast array of stimuli they are exposed to (Daft \& Weick, 1984). Organizational decision-makers are assumed to be more receptive towards prescriptions that match their personal values and prioritize initiatives that are aligned with their selective interpretation of reality (Andersson and Bateman, 2000). In other terms, managers' personal values and their subjective interpretation of organizational priorities contribute legitimizing specific issues within the organizational context, amplifying the perception of said issues as strategically relevant for the organization (Andersson and Bateman, 2000; Sharma and Good, 2013). Eventually, the managerial interpretation process is assumed to influence organizations' agenda-setting, channelling resources and organizational commitment towards issues deemed strategically salient (Dutton \& Jackson, 1987).

Based on these theoretical foundations, Bansal and Roth (2000) model of ecological responsiveness consider organizational members' concern for the natural environment as a salient endogenous contextual factor to companies' proactive environmental stances. Managers' individual environmental concern contributes creating an organizational context where environmental commitments are difficult to disavow and where environmental initiatives are justified both in terms of competitive or economic objectives, as well as social responsibility purposes (Bansal, 2003; Aragón-Correa et al., 2004). Despite previous studies have highlighted the importance of the human dimension in proactive environmental practices (Andersson and Bateman, 2000; Cordano \& Frieze, 2000; Bansal, 2003; Aragón-Correa et al., 2004; Sharma and Sharma, 2011), the role of managers' individual environmental concern in influencing EMS internalization has been overlooked. In line with these observations, we derive the following hypothesis:

Hypothesis 3. Managers' individual environmental concern positively influences EMS internalization, both operational and strategic.

Corporate sustainability issues challenge organizational decisionmakers to simultaneously address numerous economic, environmental and social prescriptions, which are at the same time widely divergent but strictly interdependent (Bansal, 2002; Dyllick and Hockerts, 2002). Being exposed to such complexity, organizational decision-makers are compelled to comprehend all the far-reaching implications of sustainability issues, which extend beyond the concerns for the natural environment and include concerns for the economic and social aspects of organizational action (Sharma, 2000). Accordingly, a more nuanced understanding of organizational decision-making requires acknowledging that decision-makers face ambiguities and trade-offs given by the divergent dimensions of corporate sustainability.

Studies on the cognitive determinants of managerial interpretations of sustainability issues have focused on identifying and describing 
cognitive frames, or mental models, managers use to make sense of the complexities and trade-offs associated with sustainability issues (Byrch et al., 2007; Carroll and Shabana, 2010). Instead of describing specific value orientations (as in the case of individual environmental concern), cognitive frames embody mental categories, schemas or stereotypes decision-makers employ to make sense of highly complex and ambiguous situations (Hahn et al., 2014).

Until recently, research has strongly emphasized the so-called business case of corporate sustainability as the dominant perspective on managerial responses to sustainability issues (Carroll and Shabana, 2010; Hockerts, 2015). According to this framing, companies' stances on sustainability are dominated by economic and business objectives (Carroll and Shabana, 2010). Decision-makers endorsing the business case framing of corporate sustainability envision organizational responses that are aligned with the overall business strategy, according to a "win-win" rationale (Van der Byl and Slawinski, 2015). Similar cognitive frames ground on a unitary and non-contradicting perspective of the social, economic and environmental dimensions of corporate sustainability, which leads to excluding social or environmental prescriptions when incompatible with profit maximization (Smith et al., 2013). By excluding ambiguities, interdependencies and trade-offs, such focus allows decision-makers to reduce the complexity of sustainability issues and swiftly opt for straightforward organizational responses to issues deemed relevant to their economic objectives (Hahn et al., 2014).

More recently, research has acknowledged the existence of cognitive styles characterized by a more integrative understanding of the multiple implications entailed by corporate sustainability issues, i.e. the socalled paradoxical case (Hahn et al., 2014; Van der Byl and Slawinski, 2015). Managers owing a similar cognitive frame are more prone to appreciate competing prescriptions, being capable to embrace diverse stakeholders' perspectives and needs. Due to a more inclusive understanding of the social, economic and environmental dimensions of sustainability issues, managers displaying a paradoxical cognitive style are assumed to endorse a more prudent or precautionary stance on environmental issues and consider more comprehensive organizational responses (Smith et al., 2013), if compared to organizational responses driven by more exclusive and simplistic views of sustainability issues.

Despite the relation between decision-makers' mental models and sustainability performance is largely unexplored, organizations whose managers endorse a predominantly paradoxical frame are assumed to achieve higher level of corporate sustainability performance thanks to their willingness to listen and attend to diverse prescriptions and pressures (Wong et al., 2011; Hockerts, 2015). Accordingly, we posit that managers displaying a paradoxical frame are more prone to embrace the strategic internalization of the EMS as a mean to address a larger array of external and internal pressures. This implies actively participating in the EMS as a support tool for decision-making and strategic planning to comprehend wider societal demands for better environmental responsibility, enhanced transparency and improved environmental performance (Qi et al., 2012).

At the same time, a paradoxical frame would imply a prudent approach to the operational internalization of the EMS, because of a higher awareness of tensions and trade-offs underlying organizational responses to sustainability issues (Hahn et al., 2014). Managers displaying a paradoxical frame may indeed understand the need of bold and comprehensive organizational responses to environmental issues, but may eventually fail to deploy effective solutions due to ambivalence or prudence. Accordingly, we formulate the following hypothesis:

Hypothesis 4.a. Managers' paradoxical framing of environmental practices positively influences strategic EMS internalization, but it does not influence operational internalization.

Managers displaying a business case framing of corporate sustainability are expected to adopt a pragmatic stance with regard to sustainability issues (Hahn et al., 2014). This implies addressing narrowly selected sustainability issues, whose connections with the economic objectives of the company have been ascertained and whose solutions fit within existing strategies (Carroll and Shabana, 2010). These managers are assumed to avoid opting for innovative or radical organizational responses, but rather prefer incremental and workable adaptations of existing practices (Hahn et al., 2014).

These considerations suggest a positive relation between managers' business case framing of corporate sustainability and operational EMS internalization. First, in contrast to other voluntary tools for CSR, certifiable EMS are management tools with a very specific, pragmatic and workable aim, i.e. improving companies' environmental management practices according to verifiable guidelines (Heras-Saizarbitoria et al., 2011). Second, EMS internalization is achieved by means of continuous investments in incrementally improving and fine-tuning environmental management practices (Iraldo et al., 2009). Therefore, operational internalization is expected to increase with the maturity of the EMS, rather than occurring by means of radical and disruptive interventions. Third, benefits of EMS implementation are expected to increase with internalization, especially in terms of better environmental performance and, consequently, enhanced business performance (Darnall et al., 2008; Iraldo et al., 2009; Testa et al., 2014).

Following the "win-win" logic, managers aiming at securing benefits in terms of efficiency, cost-reductions or competitive positioning, are expected to opt for internalizing certifiable EMS requirements, rather than settling for a symbolic adoption. At the same time, such alignment logic leads to overlooking prescriptions that diverge from companies' strategic scope and economic objective, because of a limited appreciation of the wider implications of environmental issues. This suggests that managers displaying a narrow perspective on environmental issues are less prone to actively participate in the EMS, ignoring its implications for decision-making and strategic planning. Based on these observations, the following hypothesis:

Hypothesis 4.b. Managers' business case framing of environmental practices positively influences operational EMS internalization, but it does not influence strategic internalization.

\section{Method}

\subsection{Data collection and sample description}

Hypothesis were tested on primary data from ISO 14001-certified and EMAS-registered companies located in diverse EU member states. Data were collected by means of a self-administered online questionnaire. Initially, the questionnaire was developed in Italian and English by the authors of the present study. Then, the questionnaire was translated in German, Polish and Spanish by fellow mother-tongue researchers in order to facilitate respondents from different nationalities. Translators' expertise in environmental management research field granted that the translations were not only linguistically equivalent, but also thematically, culturally and psychometrically equivalent, as the translators possessed working knowledge of the topic of the study. Accordingly, content validity was not pre-tested within a sample of respondents as translators' expertise in the research field already guaranteed the reliability of the measurement tool.

Environmental managers in EMAS-registered and ISO 14001-certified companies were chosen as the best informants for the study. Environmental departments are usually appointed to develop companies' strategies with regard to environmental issues, adapt organizational practices according to EMS requirements and develop relevant documentation. As far as concerns EMAS adopters, email addresses of the environmental manager in all 3963 EMAS-registered were obtained from the official EU EMAS Register. With regard to ISO 14001 adopters, we relied on contact lists of environmental managers in ISO 14001certified firms provided by accreditation and licensing bodies in different Member States. This approach was necessary as an official and updated ISO 14001 certification database does not exist. Then, the 
survey relied on a "snowball sampling" approach for further disseminating the questionnaire among ISO 14001 adopters (Biernacki and Waldorf, 1981). Accreditation and licensing bodies and other key stakeholders were invited to disseminate the questionnaire among certified companies in order to increase the number of respondents. As a consequence, it is not possible to estimate the total number of ISO 14001-certified organizations that received the survey via email.

Next, questionnaires were uploaded onto an online survey platform and environmental managers were emailed the introductory letter containing a web link for accessing the questionnaire. The landing page of the questionnaire included detailed instructions on how to complete the questionnaire. The questionnaire remained online and available from early April 2017 to the end of May 2017. During this time span, reminder emails were sent every two weeks.

After this timespan, 742 EMAS-registered organizations participated in the online questionnaire, giving an overall response rate of $18.7 \%$. However, once incomplete questionnaires have been discarded, 390 completed questionnaires were retained for analysis, representing a $10.3 \%$ response rate. As far as concern ISO 14001 respondents, 225 certified organizations took part in the survey. However, completed questionnaires amounted to only 64 respondents. Therefore, the total final sample amounts to 457 respondents, which is a considerably larger sample if compared to similar studies (e.g. Sharma, 2000).

Not surprisingly, the countries with the highest number of EMAS registrations and ISO 14001 certifications in Europe - Spain, Germany and Italy - provided the vast majority of responses, i.e. $80.4 \%$. In particular, Spanish companies account for the $29.6 \%$ of the sample, while German and Italian companies account for the $27.3 \%$ and $23.4 \%$, respectively. The final sample represents companies operating in 16 diverse Member States.

Almost half of the final sample, i.e. $45 \%$, is made up of companies operating in diverse manufacturing sectors, among which manufacturing of metal products ( $10.6 \%$ of the sample), wood products $(7.2 \%)$ and chemical products $(6.0 \%)$ are the most represented. Next, companies operating in the waste management sector are the $10.6 \%$ of the sample, while $6.9 \%$ of the sample operates in the public administration. In particular, medium companies (i.e. between 50 and 250 employees) represent the $27.7 \%$ and small companies (i.e. less than 50 employees) the 25.6\%. Large-sized companies with more than 250 employees represent the $39.6 \%$ of the sample. Lastly, micro firms with less than 10 employees are the $7.1 \%$ of the sample.

More than $80 \%$ of the EMAS-registered companies in the sample are also certified with ISO 14001. In terms of "maturity" of the EMS, the companies with the highest maturity of the certified EMS (according to EMAS or ISO 14001), i.e. more than 20 years of certification, are the $21.4 \%$ of the sample. Then, $17.2 \%$ of the companies hold a certified EMS by more than 10 years, while $24.9 \%$ by less than 10 years.

\subsection{Measures}

\subsubsection{Internalization of EMS requirements}

Most empirical studies have measured the internalization of EMS by concentrating on the extent of implementation of limited sets of specific requirements. Most commonly, studies have focused on dimensions like the integration of generic EMS requirements in daily routines (Guoyou et al., 2012; Qi et al., 2012), employees involvement (Yin and Schmeidler, 2009; Qi et al., 2012) or internal policy dissemination (Castka and Prajogo, 2013). More recently, Testa et al., (2015) advanced a more comprehensive measure of EMS internalization, by incorporating all the four pillars of the Deming Cycle - i.e. planning, operational activities, monitoring and reviewing - into a single factor. Similar approaches provide a strictly operational measure of EMS internalization, but overlook the relevant dimensions of strategic planning, top management commitment and external involvement that ultimately characterize companies' environmental proactivity (Buysse \& Verbeke, 2003; González-Benito \& González-Benito, 2006).
The extent to which the outcomes of monitoring and auditing activities are taken into consideration while establishing environmental objectives reflects the extent to which environmental practices have been integrated in the strategic planning process (González-Benito \& González-Benito, 2006). Achieving this kind of integration entails involving top managers for securing organizational commitment, at all levels of the organization, in attending to the long-term environmental objectives. Top management involvement is especially important during the key phases of designing, executing and reviewing outcomes of environmental management practices (Buysse \& Verbeke, 2003). These aspects have increasingly gained importance in certifiable EMS. As a result, the latest developments of ISO 14001:2015 explicitly aim at strengthening responsibilities and strategic involvement of organizational leaderships in executing the EMS and achieving environmental improvement (Da Fonseca, 2015).

At the same time, certifiable EMS have increasingly emphasized the importance of extending environmental management beyond companies' own environmental aspects to address issues throughout the supply-chain in a life-cycle perspective (Nawrocka et al., 2009). This implies assessing and monitoring suppliers or contractors' environmental risks and, mostly importantly, requiring suppliers to comply with the company's environmental policy through training and awareness initiatives (Nawrocka et al., 2009). Accordingly, ISO 14001:2015 makes explicit reference to involving suppliers and subcontractors in the environmental policy, according to a life cycle perspective (Da Fonseca, 2015).

A measure of EMS internalization was developed based on the dimensions of strategic planning, top management commitment and external involvement, in order to mirror aspects of corporate proactivity that are also accounted in the latest and more advanced requirements of ISO 14001:2015. In total, we developed six items describing a proactive and substantive approach to EMS implementation in terms of (1) top management commitment to EMS design and implementation, (2) top management commitment to the integration of EMS requirements, (3) strategic planning based on the result of environmental audits, (4) suppliers engagement with training and awareness initiatives, (5) suppliers monitoring through on-site and documental audits, and (6) annual test of environmental emergencies (Table 1). Respondents were asked to rate on a 5-point Likert scale their agreement with each sentence, ranging from " 1 - totally disagree" to " 5 - totally agree".

Exploratory factor analysis (EFA) confirmed two distinct factors associated with EMS internalization. The first factor includes items related to top management participation in strategic planning of environmental objectives (such as "The organization considers the results from analysis and evaluation of environmental performance, evaluation of compliance, internal audits and management review when taking action to improve"). This factor is therefore denominated "strategic EMS internalization". The second factor includes items related to the implementation of operational procedures (such as "The organization has carried on-site or documental audits involving supplier/contractors"). Accordingly, it is denominated "operational EMS internalization". The Cronbach's alpha reliability coefficient for strategic EMS internalization is 0.84 , which considerably above the recommended value of 0.6 for combining variables into a single construct (Cortina, 1993). Cronbach's alpha for operational EMS internalization is 0.6. Despite a lower value than the conventionally recommended value of 0.7 , a value close to 0.6 is considered satisfactory given the exploratory nature of the construct (Nunnally, 1978).

\subsubsection{Environmental issue salience}

Environmental issues salience denotes the extent to which local external constituents are concerned for the natural environment and are therefore likely to pay attention to companies' environmental behaviour. Respondents rated on a 5-point Likert scale their level of agreement with two items indicating high environmental issues salience on the side of the local government and local communities 
Table 1

Item scales utilized in the questionnaire.

\begin{tabular}{|c|c|}
\hline Variable & Item \\
\hline Strategic internalization & $\begin{array}{l}\text { The Top Management of my organization participates actively in the EMS also beyond the Management Review periodical meeting. } \\
\text { The Top management ensures the integration of the environmental management system requirements into the organization's business processes. } \\
\text { The organization considers the results from analysis and evaluation of environmental performance, evaluation of compliance, internal audits and } \\
\text { management review when taking action to improve. }\end{array}$ \\
\hline Operational internalization & $\begin{array}{l}\text { The organization involves suppliers in the awareness and training activities. } \\
\text { The organization has carried on-site or documental audits involving supplier/contractors. } \\
\text { The organization test environmental emergencies (e.g. oil/chemical spills) at least once a year. }\end{array}$ \\
\hline Environmental issue salience & $\begin{array}{l}\text { Local government is very concerned about environmental issues. } \\
\text { Local communities living where my organization is located consider the natural environment as an asset to preserve. }\end{array}$ \\
\hline Environmental concern & $\begin{array}{l}\text { I am concerned about the environment. } \\
\text { I am willing to make sacrifices to protect the environment. } \\
\text { The conditions of the environment affects the quality of my life. } \\
\text { My actions impact the environment. }\end{array}$ \\
\hline
\end{tabular}

(Table 2). The Cronbach's alpha reliability coefficient for this construct is 0.6. Taking into consideration the exploratory nature of the measure, the reliability coefficient is considered satisfactory (Nunnally, 1978).

\subsubsection{Regulatory incentives}

Regulatory incentives based on certified EMS adoption, especially ISO 14001 and EMAS, are available in most European countries (Glachant et al., 2002). Perceived effectiveness of regulatory reliefs or administrative benefits may considerably vary based on the typology and magnitude of the advantage granted, and based on company's characteristics (such as size, activity, location etc.). Given the subjectivity entailed by assessing the effectiveness of regulatory incentives, we measured environmental managers' satisfaction with measures of regulatory reliefs and administrative benefits provided by authorities in their Member State. Respondents were asked to rate their level of satisfaction on a 5-point Likert scale, ranging from "1 - very unsatisfied" to " 5 - very satisfied".

\subsubsection{Environmental concern}

Environmental concern denotes individuals' value orientation with regard to the natural environment (Stern and Dietz, 1994). Managers' concern for the natural environment influences individual perceptions of strategically relevant issues, by orienting their attention towards environmental aspects (Bansal, 2003). To assess the influence of managers' environmental concern on EMS internalization, the study relies on the literature on socio-physiological bases of environmental concern (Dietz et al., 1998). In particular, the present study adopts Schuhwerk and Lefkoff-Hagius (1995) four-item measure of environmental concern (Table 1). Respondents rated the items on a 5-point Likert scale, where 1 indicates a strong disagreement and 5 a strong agreement. The Cronbach's alpha reliability coefficient for this construct is 0.8 .

\subsubsection{Paradoxical framing and business case framing}

Hahn et al. (2014) delineate the paradoxical and business case framings of corporate sustainability as two opposite archetypal mental models. The two framings indeed base on divergent views of the relationship between the economic, environmental, and social dimensions of sustainability. While managers displaying a business case frame focus on environmental aspects that converge with business objectives, managers endorsing the paradoxical frame attempt at conciliating a wider spectrum of societal demands. However, actual managers' cognitive frames represent different combinations of the two opposite archetypal models, and hardly correspond in their entirety to one or the other ideal frames.

To measure managers' cognitive framing of corporate sustainability, respondents were asked to rank a list of nine potential objectives according to their importance in motivating the adoption of environmental practices, with 1 being the most important objective and 9 the least important. Potential objectives were divided between objectives typically displaying a business case frame, objectives embodying a paradoxical framing of corporate sustainability and objectives associated with regulatory and normative compliance. This latter category of objectives was included to account for compliance motivations that are, however, not directly ascribable to either the paradoxical or the business case frame (Hahn et al., 2014).

Business case objectives pointed out competitive or reputational benefits associated with environmental practices, and included (1) improving efficiency (2) gaining market share, and (3) improving reputation. Objectives displaying a paradoxical framing referred to companies' social and environmental responsibilities and included (1) fulfilling moral obligations towards the natural environment, (2) tackling salient societal issues, and (3) safeguarding the common good. Objectives associated with regulatory and normative compliance included (1) achieving compliance to environmental laws, (2) satisfying shareholders' expectations, and (3) gaining legitimacy in the eyes of shareholders.

Based on this ranking, two categorical variables were created for business case frame and paradoxical frame, while compliance motivations were not considered for the sake of the present study. The two variables range from 0 to 2 on the base of the number of objectives pertaining to the two framings that were ranked among the first three positions. The absence of the value 3 in both categorical variables confirms that managers rarely conform entirely to an archetypal mental model. The value 0 occurs very rarely in the business case variable, indicating that the large majority of the respondents display some features of the business case frame. On the other hand, the value 0 occurs frequently in the paradoxical frame variable, indicating that almost half of the respondents' framings of corporate sustainability is far from the archetypal paradoxical frame.

\subsubsection{Control variables}

Three variables were therefore accounted as control variables, i.e. certification according to EMAS, size of the company (i.e. number of employees) and maturity of the EMS (i.e. years from adoption).

EMAS certification - Despite ISO 14001 requirements have been fully integrated in the EMAS Regulation in 2001, few significant characteristics still differentiate the two standards (Neugebauer, 2012). According to ISO 14001 , certification is issued by private environmental verifiers and it is not officially approved by any public bodies. EMAS requires national public bodies (i.e. national EMAS Competent Bodies) to carry out the verification processes leading up to registration (Testa et al., 2014). Moreover, EMAS requirements provide a more detailed specification of the EMS compared to ISO 14001, especially in terms of external communication (i.e. publication of the Environmental Statement) and verification of full legal compliance (Heras-Saizarbitoria et al., 2016). As these differences may potentially influence companies' approach to the EMS, a binary variable was created to account for certification with EMAS. 


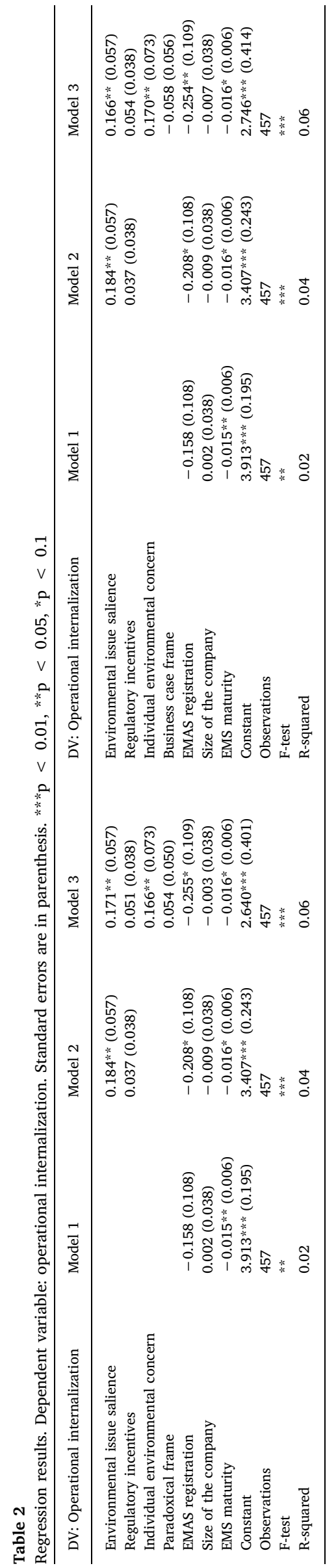

Size of the company - Firm's size has been frequently adopted as a proxy of companies' resources. Small companies often suffer resource constraints that limit their capacity to invest slack resources in environmental practices (Aragón-Correa and Sharma, 2003). Therefore, company's size in terms of number of employees was measured by means of a multiple-choice question. Accordingly, we developed a categorical variable, dividing respondents between micro, small, medium and large firms.

Maturity of the EMS - Internalization of EMS requirements within daily operational practices is expected to increase with time and with the "maturity" of the EMS (Iraldo et al., 2009). Accordingly, respondents were asked to indicate the year in which their organizations received the first official certification. We measured EMS maturity in terms of number of years since the first certification. The variable ranges from 1 year to 25 years.

\section{Results}

Given the two sets of predictors (i.e. exogenous and endogenous contextual factors), hierarchical regression was chosen as the most appropriate method for testing the hypothesis of the study. Differently from other multiple regression methods, hierarchical regression is specifically suited for testing theory-driven relations between a dependent variable and different sets of predictors, which are sequentially entered in the analysis (Petrocelli, 2003). Indeed, in hierarchical regressions, the focus is on the incremental increase in model predictability, i.e. the amount of variance explained, associated with each additional set of predictors. This method has been largely adopted in management system research to test the influence of diverse institutional, organizational or managerial antecedents on adoption and performance of similar management tools (Khidir ElTayeb et al., 2010; Nee, 2011; Gimenez-Espin et al., 2013; Rashid and Shami, 2017).

Accordingly, two hierarchical regressions were performed in order to test the relations with both dependent variables, i.e. operational internalization and strategic internalization. Results are displayed in Table 2 for operational internalization and in Table 3 for strategic internalization.

Model 1 includes only the control variables (i.e. certification with EMAS, size of the company and EMS maturity). Model 2 adds the exogenous contextual factors as predictors (i.e. environmental issue salience and regulatory incentives), and Model 3 adds the endogenous contextual factors (i.e. environmental concern and paradoxical frame or business case frame). Given a strong negative correlation between the two opposite mental models (Table 4), the two variables describing managers' cognitive framings of corporate sustainability are included in two distinct models. Therefore, the left-side of both Tables 2 and 3 includes the results of the model with the paradoxical frame variable, while the right-sides include results of the model with the business case frame variable.

In all models, the F-test is statistically significant ( $\mathrm{p}<0.05$ in Model 1, p $<0.01$ in Model 2 and 3), and explanatory variables increasingly contribute to the amount of explained variance.

\subsection{Results for operational EMS internalization}

As far as concerns the explained variance of operational internalization (Table 2), at Model 2 the R-squared increases from 0.02 to 0.04 and the difference is statistically significant at $p<0.01$. In Model 3 , the R-squared increases to 0.06 with statistical significance $\mathrm{p}<0.05$, both with paradoxical frame or business case frame.

According to Model 1, the control variables explain a very limited amount of operational internalization. In particular, only EMS maturity is significant in Model 1. Interestingly, the relation coefficient is negative, indicating an inverse relation between the number of years from the first EMS certification and the extent of internalization of EMS requirements in operational processes. This result stays constant also in 


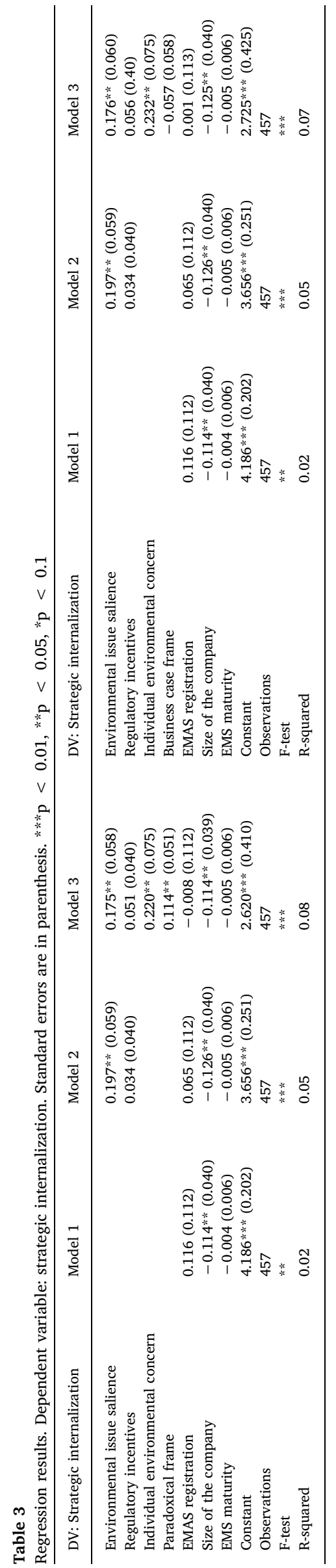

Model 2 and 3. EMAS certification becomes significant in Model 2 and 3. As in the case of EMS maturity, the relation coefficient indicates an inverse relation between EMAS adoption and operational internalization.

Model 2 displays results for the relations between exogenous contextual factors (i.e. environmental issue salience and regulatory incentives) and operational internalization. The results indicate a positive and significant relation between environmental issues salience and operational internalization (Hypothesis 1 ), with $\beta=0.184$, $\mathrm{SE}=0.057$ and statistical significance $\mathrm{p}<0.05$. On the other hand, the relation between regulatory incentives and operational internalization is not significant, therefore Hypothesis 2 is not supported.

Model 3 displays results for the relations between operational internalization and the endogenous contextual factors, i.e. managers' individual environmental concern and the two cognitive framings of corporate sustainability. The results indicate a positive relation between individual environmental concern and operational internalization (Hypothesis 3), with $\beta=0.170, \mathrm{SE}=0.073$ and statistical significance $\mathrm{p}<0.05$. Interestingly, nor the paradoxical or business case framing of corporate sustainability are significantly related with operational EMS internalization. Accordingly, both Hypothesis 4.a and 4.b are not supported by the results concerning operational EMS internalization.

\subsection{Results for strategic EMS internalization}

As far as concerns the explained variance of strategic internalization (Table 3), at Model 2 the R-squared increases from 0.02 to 0.05 with statistical significance $p<0.01$. At Model 3, when paradoxical frame is added to the model, the R-squared increases to 0.08 with statistical significance $\mathrm{p}<0.01$. On the other hand, when business case frame is added to the model, the R-squared increases to 0.07 at statistical significance $\mathrm{p}<0.01$.

Control variables explain very limited variance in Model 1. In particular, companies' size is the only significant control variable in all the three models. Exogenous contextual factors are included in Model 2. As in the case of operational internalization, the results highlight a positive and significant relation between environmental issue salience and strategic internalization (Hypothesis 1 ), with $\beta=0.197, \mathrm{SE}=0.059$ and statistical significance $\mathrm{p}<0.05$. On the other hand, the relation between regulatory incentives and strategic internalization is not significant, therefore Hypothesis 2 is not supported.

Model 3 displays the results of the relation between endogenous contextual factors and strategic internalization. Managers' individual environmental concern is positively related with the dependent variable, $\beta=0.220, S E=0.075$ and statistical significance $p<0.05$. Accordingly, Hypothesis 3 is supported. As far as concerns the relation between managers' mental models and strategic internalization, the results highlight, on the one hand, a positive and significant relation between the paradoxical framing of corporate sustainability and strategic internalization $(\beta=0.114, \mathrm{SE}=0.051$ and statistical significance $\mathrm{p}<0.05$ ), providing support for Hypothesis 4.a. On the other hand, the relation between the business case framing of sustainability and strategic internalization is not significant, therefore Hypothesis 4.b is not supported.

A summary of the results is provided in Table 5 .

\subsection{Robustness of the model}

Several tests were performed to assess the robustness of the model. First, we assessed the normality of residuals by plotting the non-parametric Kernel density estimator, which highlighted symmetry in the distribution of residuals (Fan and Gencay, 1995). We also performed the Shapiro Wilk test to assess normality in residuals distribution. Second, we performed Breusch-Pagan test to assess homogeneity of the variance of the residuals. The test revealed that heteroscedasticity does 
Table 4

Descriptive statistics and correlations. Starred correlations are significant at *p $<0.01,{ }^{*} \mathrm{p}<0.05$, ***p $<0.1$

\begin{tabular}{|c|c|c|c|c|c|c|c|c|c|c|c|c|c|c|}
\hline & & Mean & S.D. & Min & $\operatorname{Max}$ & 1 & 2 & 3 & 4 & 5 & 6 & 7 & 8 & 9 \\
\hline 1 & Strategic internalization & 3.87 & 0.81 & 1.21 & 5.06 & & & & & & & & & \\
\hline 2 & Operational internalization & 3.55 & 0.79 & 0.99 & 5.40 & $0.40^{* * *}$ & & & & & & & & \\
\hline 3 & Environmental issue salience & 2.74 & 0.64 & 0.80 & 4.00 & $0.15^{* * *}$ & $0.15^{* * *}$ & & & & & & & \\
\hline 4 & Regulatory incentives & 2.52 & 0.96 & 1.00 & 5.00 & $0.08^{*}$ & 0.04 & $0.14^{* * *}$ & & & & & & \\
\hline 5 & Environmental concern & 4.50 & 0.50 & 1.86 & 5.06 & $0.14^{* * *}$ & $0.09 * *$ & 0.05 & $-0.14^{* * *}$ & & & & & \\
\hline 6 & Paradoxical frame & 0.78 & 0.73 & 0.00 & 2.00 & $0.14^{* * *}$ & 0.07 & $0.08^{*}$ & 0.05 & $0.10 * *$ & & & & \\
\hline 7 & Business case frame & 1.11 & 0.64 & 0.00 & 2.00 & $-0.08^{*}$ & $-0.08 *$ & $-0.16^{* * *}$ & 0.02 & $-0.07^{*}$ & $-0.60^{* * *}$ & & & \\
\hline 8 & EMAS certification & 0.86 & 0.34 & 0.00 & 1.00 & 0.06 & -0.05 & $0.10^{* * *}$ & $0.11^{* *}$ & $0.13^{* * *}$ & $0.13^{* * *}$ & $-0.10 * *$ & & \\
\hline 9 & Size of the company & 3.00 & 0.97 & 1.00 & 4.00 & $-0.14^{* * *}$ & 0.02 & $0.11^{* *}$ & $-0.09 * *$ & 0.01 & $-0.12^{* * *}$ & -0.01 & $-0.07^{\star}$ & \\
\hline 10 & Maturity of the EMS & 14.67 & 6.04 & 1.00 & 25.00 & -0.01 & $-0.12 * *$ & 0.00 & 0.07 & -0.00 & 0.00 & 0.04 & -0.02 & $-0.20 * * *$ \\
\hline
\end{tabular}

not affect the model. Third, variance inflation factor (VIF) was measured for all variables to verify the presence of multicollinearity. The results show a mean VIF considerably lower than 5 , variance inflation factors lower than 2.0 for all variables, and tolerance levels higher than 0.1. Accordingly, multicollinearity does not emerge as a concern (Kennedy, 2003).

\subsection{Addressing common method variance}

While designing the questionnaire, several remedies were adopted in order to avoid bias that commonly affect behavioural research, such as social desirability bias and common method variance. Accordingly, the questionnaire avoided any questions concerning the name of the respondent or the name of the organization, with the aim to reduce social desirability bias by granting respondent anonymity. Furthermore, an introductory letter explicitly guaranteed the independent aim of the study and that data would only be revealed in an aggregated form (King and Bruner, 2000; Tourangeau and Yan, 2007). In order to avoid vagueness, questions were kept simple and concise. Furthermore, most questions employed a 1-5 Likert scale to reduce ambiguity in answers by providing respondents with a range of values to choose from. Questions based on categorical Likert scales included verbal labels for the endpoints and midpoints of the scales (Podsakoff et al., 2003).

Beside procedural remedies, we performed the Harman's one-factor test to check for the presence of common method variance. The results reveal six factors with eigenvalues higher than 1.0, of which the largest accounted for $18 \%$ of the variance. Accordingly, it is reasonable to claim that substantial common method variance is not present (Steensma et al., 2005). Lastly, we performed the regression specification error test to check for omitted variables, which did not reveal any model specification errors (Ramalho et al., 2011). Furthermore, the correlation matrix (Table 4) shows the absence of strong correlations among all the variables, apart from the negative correlation between the paradoxical frame and the business case frame.

\section{Discussion and conclusions}

\subsection{Contribution to the literature}

The objective of the study is investigating the role of exogenous and endogenous contextual factors in the substantive internalization of certifiable EMS, with a focus on ISO 14001 and EMAS. Drawing on insights from Bansal and Roth (2000) model of ecological responsiveness, the study advances a cognitive perspective on proactive environmental strategies (Potrich et al., 2019), by examining managers' perceptions and interpretation of field-level contextual factors and managerial interpretations of sustainability issues that influence EMS internalization.

The study contributes to the literature in several ways. First, by identifying two distinct dimensions of EMS internalization (i.e. operational and strategic internalization), the study contributes to a more nuanced understanding of management system internalization. Previous literature have mostly focused on the operational aspects of internalization associated with the substantive implementation of the Deming cycle (Link and Naveh, 2006; Nair \& Prajogo, 2009; HerasSaizarbitoria, 2011, Martín-de Castro et al., 2017; Testa et al., 2018a,b). The present research highlights a further dimension of this phenomenon, which emphasises the role of the top management in executing the management system and its implications for decision-making and strategic planning purposes.

The measure of strategic internalization indeed mirrors the latest developments of the ISO standards (such as the latest revision of ISO 14001:2015), whose additional requirements entail a stronger coupling between the management system and companies' strategic orientations by means of a stronger involvement of the top management ( $\mathrm{Da}$ Fonseca, 2015). In developing this measure, the study integrates insights from previous studies concerning top management leadership and commitment as a crucial success factor in each stage of the EMS adoption and maintenance processes (Zutshi \& Sohal, 2004).

The distinction of the strategic and operational dimensions in two separate constructs adds to the position that coupling environmental commitment with strategic direction entails a symbolic form of corporate environmentalism if not contingent upon the substantive

Table 5

Summary of the study's results.

\begin{tabular}{|c|c|c|c|}
\hline & & \multicolumn{2}{|l|}{ Dependent variables } \\
\hline \multicolumn{2}{|c|}{ Hypothesis of the study } & Operational internalization & Strategic internalization \\
\hline Hypothesis 1 & Environmental issue salience positively influence EMS internalization. & Supported & Supported \\
\hline Hypothesis 2 & Regulatory incentives positively influence EMS internalization. & Not supported & Not supported \\
\hline Hypothesis 3 & Managers' individual environmental concern positively influence EMS internalization. & Supported & Supported \\
\hline Hypothesis 4.a & $\begin{array}{l}\text { Managers' paradoxical framing of environmental practices positively influence strategic EMS internalization, } \\
\text { but it does not influence operational internalization. }\end{array}$ & Supported & Supported \\
\hline Hypothesis 4.b & $\begin{array}{l}\text { Managers' business case framing of environmental practices positively influence operational EMS } \\
\text { internalization, but it does not influence strategic internalization. }\end{array}$ & Not supported & Supported \\
\hline
\end{tabular}


implementation of the EMS requirements (Bowen, 2014). In this perspective, certifiable EMS adoption appears as a mean to reconcile environmental stances and strategic posture, which, however, does not prevent the potential decoupling between symbolic environmental commitment and substantive environmental improvement (Martín-de Castro et al., 2017).

Second, the study contributes to the literature on the strategic interpretation of environmental issues (Bansal and Roth, 2000; Bansal, 2003), by investigating managers' interpretations of exogenous and endogenous contextual factors encouraging organizational responses in terms of EMS internalization. As far as concerns the factors pertaining to the external context, the results point out that local stakeholders' attention on environmental issues encourages EMS internalization, both at the strategic and operational level. This result suggests that decisionmakers opt for a substantive implementation of the EMS to avoid backlashes in contexts characterized by high public attention on environmental issues, especially from local communities and public authorities.

This result contributes to the long debated relation between stakeholders' pressures and EMS internalization. Previous research has indeed provided inconclusive results at this regard: while some scholars argued that external stakeholders' pressures lead to a symbolic EMS adoption for legitimation purposes (Aravind and Christmann, 2011; Castka and Prajogo, 2013), other studies highlighted a positive relation between intensity of stakeholders' pressures and substantive internalization (Christmann and Taylor, 2006). This result supports previous contributions arguing that external contextual factors influence how companies respond to pressures exerted by stakeholders, by shaping motivations for the substantive or symbolic EMS adoption (Perez-Batres et al., 2012; Iatridis and Kesidou, 2018). Similar results suggest that external contextual factors could significantly moderate the relation between stakeholders' pressures and EMS internalization. Accordingly, future research could build on these findings to investigate the moderating effect of external contextual factors (pertaining to the economic, social and natural environment) on the relation between companies' exposure to stakeholders' pressures and EMS substantive internalization.

The study also contributes to the debate surrounding regulatory incentives for voluntary standards adoption (Anton et al., 2004; Wätzold et al., 2011). Despite previous studies have supported similar regulatory measures as effective tools for enhancing certifiable EMS adoption in given regional or national contexts (Wätzold et al., 2011; Daddi et al., 2016; Testa et al., 2016), the results of the present study asserts that regulatory reliefs or administrative benefits are not effective in creating favourable contextual conditions for EMS internalization. This latter result suggests that, in the presence of regulatory incentives based on certifiable EMS, managers may opt for a symbolic adoption of the certification to take advantage of regulatory benefits. Accordingly, the present research adds to previous calls for reassessing existing regulatory relief measures in light of evidences that question the effectiveness of similar tools in fostering environmental improvement ( 3 Heras-Saizarbitoria et al., 2013). At this regard, further research is necessary to clarify which typologies of regulatory benefits need to be promoted in order to foster a substantive approach to EMS implementation and reduce risk of superficial EMS adoption. Accordingly, future studies should differentiate regulatory relief measures based on types of benefits (e.g. permit extension, fiscal reliefs, lower inspection frequency etc.) in order to discern effective policies from fruitless measures.

As far as concerns the endogenous contextual factors, the study indicates managers' environmental concern as an antecedent of both strategic and operational internalization. This result supports previous findings highlighting managers' concern for the natural environment as a crucial enabler of the strategic issue interpretation process underlying organizational responses to environmental issues (Sharma and Good, 2013; Andersson and Bateman, 2000). In this perspective, the study underlines the crucial role of normative issue characteristics in eliciting organizational responses to environmental issues (Bansal, 2003). At this regard, most studies have emphasized the instrumental aspects of environmental issues (Aragon-Correa \& Rubio-Lòpez, 2007; Boiral et al., 2018), overlooking the values and affective dimensions that, by provoking individuals' apprehension and concern, elicit organizational action (Hemingway, 2005).

The study also contributes to the debate surrounding managers' cognitive framings of corporate sustainability (Hahn et al., 2014), by testing relations between two divergent framings of proactive environmental practices and EMS internalization. On the one hand, the study highlights the absence of significant relationships between the business case frame and EMS internalization. This result questions the "win-win paradigm" of corporate sustainability (Carroll and Shabana, 2010), indicating that managers' adherence to an alignment logic between environmental and business objectives does not influence EMS internalization. Indeed, as suggested by Hahn et al. (2015), a pragmatic stance on environmental issues may limit proactivity and favour a superficial EMS adoption to secure competitive advantages in the short term. Accordingly, the study adds to previous criticism of the business case of corporate environmentalism, suggesting that a "win-win" approach to the adoption of certifiable EMS may incentivize a symbolic implementation for short-term reputational or commercial purposes (Hockerts, 2015). The results indeed support previous contributions by Hockerts (2015) indicating that companies with lower environmental performance are characterized by a dominant "business case" approach to sustainability issues.

On the other hand, the relation between a paradoxical frame and internalization is controversial. While similar framings do not appear to influence the operational internalization of the EMS, our results support a positive relationship with strategic internalization. This result suggests that managers acknowledging the complexity of environmental issues are more prone to participate in the EMS and account for its outcomes in the decision-making process, possibly as a mean to address wider societal demands. However, as supported by Hahn et al., (2015), a prudent stance on sustainability issues shies managers from fully implementing environmental practices and hampers their ability to implement workable solutions. At the same time, the absence of a significant relation with operational internalization corroborates the argument that a stronger coupling between companies' environmental commitment and strategic direction is often disjointed from the internalization of EMS requirements at the operational level.

This latter result points to a form of decoupling between formal structures at the managerial level (e.g. top management involvement in the EMS) and actual practices at the operational level. Accordingly, the study adds to the conceptualization of symbolic corporate environmentalism as a more sophisticated and subtle form of greenwashing (Bowen, 2014), which emphasise the more symbolic dimensions of environmental practices by means of shared meanings and broadly legitimated images, while decoupling from the material and substantive dimensions of environmental performance (Bowen and Aragon-Correa, 2014).

\subsection{Managerial implications}

The study highlights that the adoption of certifiable EMS often constitutes symbolic corporate environmentalism, due to the limited internalization of EMS requirements in companies' daily procedures. This is especially the case if the most advanced features of ISO 14001 and EMAS are taken into consideration, such as applying a life-cycle perspective on the assessment of salient environmental aspects or having suppliers and contractors to comply with the environmental policy. The study suggests that symbolic corporate environmentalism may even occur when top managers' display of commitment and participation to the EMS is decoupled from the internalization of EMS requirements at the operational level. These conclusions point out that 
many managers still consider certifiable EMS as marketing tools rather than management tools for environmental improvement, because environmental benefits largely depend on the substantive internalization of EMS requirements.

Further implications derive from recognising that contextual conditions, both external and internal, are not neutral, but play a role in shaping motivations for substantive EMS internalization. First, the role of environmental issue salience in the local context entails managers to assess and monitor stakeholders' sensibilities with regard to their environmental aspects. This implies strengthening the role of the EMS as an interface between the company and local stakeholders, and as a source of transparent, updated and reliable information on the company's environmental performance. This objective also involves increasing stakeholders' awareness of environmental certifications and, at the same time, encouraging stakeholders to directly address certified companies about the substantive implementation of environmental practices.

Second, the study questions the effectiveness of governmental regulatory reliefs based on certifiable EMS in incentivizing a substantive approach to EMS implementation, rather than a mere symbolic adoption. This point to the necessity to design better regulatory incentives targeting the internalization of EMS requirements, rather than certification. Regulatory incentives could be contingent upon achieving documented environmental improvements and require evidence of substantive internalization of the EMS, in order to avoid opportunistic behaviours. A similar approach could also regulate the verification and certification processes carried out by licensing bodies, in order to strengthen the role of verifiers in reducing the risk of symbolic EMS adoption.

Finally, as far as concern the endogenous factors examined, the study highlights the importance of nurturing an organizational context supporting members' concern for the natural environment. Managers' environmental concern can be activated through education, training and awareness initiatives, informing organizational members about the role of the private sector in environmental degradation and highlighting what efforts can be implemented to tackle environmental challenges. At the same time, companies could hire individuals characterized by strong environmental commitment in order to facilitate legitimizing environmental issues within the organizational context. Training and education initiatives are also needed to increase managers' awareness of the benefits associated with EMS internalization, in order to contrast widespread perceptions of environmental certification as a short-term reputational benefit.

\subsection{Limitations and avenues for future research}

Exploring the limitations of the present study helps identifying avenues for future research. First, the study focuses on a limited set of exogenous and endogenous contextual factors. Despite not covered in this study, further factors shape contextual conditions that may influence the internalization of proactive environmental practices. At the organizational level, future studies could focus on investigating organizational values underlying the substantive or symbolic internalization of certifiable EMS (Bansal, 2003). In particular, research should focus on how organizational values and culture support or hamper individuals' concerns for the natural environment in influencing internalization. As individual concerns are posited to arise out of cognitive dissonance between individuals' expectations and reality (Stern and Dietz, 1994), highly concerned managers could display a more proactive approach in organizational contexts characterized by a weaker environmental culture. Similar studies may indeed contribute advancing the understanding of conflicting dynamics between divergent institutional logics within the organizational context and their influence on organizational responses to environmental issues (Greenwood et al., 2010).

Second, the study builds upon a unique source of data. Despite procedural remedies have been adopted to reduce potential social desirability bias, respondents' tendency to overestimate certain aspects of their organizational context could result in an overestimation bias. Future studies should therefore attempt at triangulating the results by combining diverse data collection methods (such as questionnaires and interviews), or by combining diverse sources within the same organization. Besides reducing overestimation bias, similar studies could contribute to a better understanding of how dominant cognitive framings of corporate sustainability are shaped within the organizational context (Hahn \& Aragon-Correa, 2015). By surveying several organizational members, research could acknowledge the coexistence of conflicting mental models and investigate how cognitive plurality contributes increasing the heterogeneity of organizational responses to environmental issues (Hahn et al., 2010).

\section{References}

Álvarez García, J., del Río, M.D.L.C., Saraiva, M., Pires, A.R., 2018. The influence of motivations and barriers in the benefits. An empirical study of EMAS certified business in Spain. J. Clean. Prod. 185, 62-74.

Andersson, L.M., Bateman, T.S., 2000. Individual environmental initiative: championing natural environmental issues in U.S. business organizations. Acad. Manag. J. 43, 548-570.

Anton, W.R.Q., Deltas, G., Khanna, M., 2004. Incentives for environmental self- regulation and implications for environmental performance. J. Environ. Econ. Manag. 48 (1), $632 \mathrm{e} 654$.

Aragón-Correa, J.A., Rubio-Lopez, E.A., 2007. Proactive corporate environmental strategies: myths and misunderstandings. Long Range Plan. 40 (3), 357-381.

Aragón-Correa, J.A., Sharma, S., 2003. A contingent resource-based view of proactive corporate environmental strategy. Acad. Manag. Rev. 28 (1), 71-88.

Aragón-Correa, J.A., Matías-Reche, F., Senise-Barrio, M.E., 2004. Managerial discretion and corporate commitment to the natural environment. J. Bus. Res. 57, 964-975.

Aravind, D., Christmann, P., 2011. Decoupling of standard implementation from certification: does quality of ISO 14001 implementation affect facilities' environmental performance? Bus. Ethics Q. 21 (1), 73-102.

Bansal, P., 2002. The corporate challenges of sustainable development. Acad. Manag. Exec. 16, 122-131

Bansal, P., 2003. From issues to actions: the importance of individual concerns and organizational values in responding to natural environmental issues. Organ. Sci. 14 (5), $510-527$.

Bansal, P., Hunter, T., 2003. Strategic explanations for the early adoption of ISO 14001. J. Bus. Ethics 46 (3), 289-299.

Bansal, P., Roth, K., 2000. Why companies go green: a model of ecological responsiveness. Acad. Manag. J. 43 (4), 717-736.

Biernacki, P., Waldorf, D., 1981. Snowball sampling: problems and techniques of chain referral sampling. Socio. Methods Res. 10 (2), 141-163.

Boiral, O., Guillaumie, L., Heras-Saizarbitoria, I., Tayo Tene, C.V., 2018. Adoption and outcomes of ISO 14001: a systematic review. Int. J. Manag. Rev. 20 (2), 411-432.

Bowen, F., 2014. After Greenwashing: Symbolic Corporate Environmentalism and Society. Cambridge University Press, Cambridge, England.

Bowen, F., Aragon-Correa, J.A., 2014. Greenwashing in corporate environmentalism research and practice: the importance of what we say and do. Organ. Environ. 27, $107-112$.

Byrch, C., Kearins, K., Milne, M.J., Morgan, R., 2007. Sustainable "what"? A cognitive approach to understanding sustainable development. Qual. Res. Account. Manag. 4 (1), 26-52.

Buysse, K., Verbeke, A., 2003. Proactive environmental strategies: A stakeholder management perspective. Strat. Manag. J. 24 (5), 453-470.

Carroll, A.B., Shabana, K.M., 2010. The business case for corporate social responsibility: a review of concepts, research and practice. Int. J. Manag. Rev. 12, 85-105.

Castka, P., Prajogo, D., 2013. The effect of pressure from secondary stakeholders on the internalization of ISO 14001. J. Clean. Prod. 47, 245-252.

Christmann, P., Taylor, G., 2006. Firm self-regulation through international certifiable standards: determinants of symbolic versus substantive implementation. J. Int. Bus. Stud. 37, 863-883.

Cordano, M., Frieze, I.H., 2000. Pollution reduction preferences of US environmental managers: Applying Ajzen's theory of planned behavior. Acad. Manag. J. 43 (4), $627-641$.

Cortina, J.M., 1993. What is coefficient alpha? An examination of theory and applications. J. Appl. Psychol. 78 (1), 98.

D’Souza, C., Marjoribanks, T., Young, S., Sullivan Mort, G., Nanere, M., John, J.J., 2019. Environmental management systems: an alternative marketing strategy for sustainability. J. Strat. Market. 27 (5), 417-434.

Da Fonseca, L.M.C.M., 2015. ISO 14001: 2015: an improved tool for sustainability. J. Ind. Eng. Manag. 8 (1), 37-50.

Daddi, T., Magistrelli, M., Frey, M., Iraldo, F., 2011. Do environmental management systems improve environmental performance? Empirical evidence from Italian companies. Environ. Dev. Sustain. 13, 845-862.

Daddi, T., Testa, F., Frey, M., Iraldo, F., 2016. Exploring the link between institutional pressures and environmental management systems effectiveness: an empirical study. J. Environ. Manag. 183, 647-656.

Daft, R.L., Weick, K.E., 1984. Toward a model of organizations as interpretation systems Acad. Manag. Rev. 9 (2), 284-295.

Darnall, N., 2006. Why firms mandate ISO 14001 certification. Bus. Soc. 45, 354-381. 
Darnall, N., Henriques, I., Sadorsky, P., 2008. Do environmental management systems improve business performance in an international setting? J. Int. Manag. 14 (4), 364-376.

Delmas, M.A., Toffel, M.W., 2008. Organizational responses to environmental demands: opening the black box. Strat. Manag. J. 29 (10), 1027-1055.

Delmas, M., Toffel, M.W., 2004. Stakeholders and environmental management practices: an institutional framework. Bus. Strateg. Environ. 13 (4), 209-222.

Demirel, P., Iatridis, K., Kesidou, E., 2018. The impact of regulatory complexity upon selfregulation: evidence from the adoption and certification of environmental management systems. J. Environ. Manag. 207, 80-91.

Dietz, T., Stern, P.C., Guagnano, G.A., 1998. Social structural and social psychological bases of environmental concern. Environ. Behav. 30 (4), 450-471.

Dyllick, T., Hockerts, K., 2002. Beyond the business case for corporate sustainability. Bus. Strateg. Environ. 11 (2), 130-141.

Dutton, J.E., Jackson, S.E., 1987. Categorizing strategic issues: Links to organizational action. Acad. Manag. Rev. 12 (1), 76-90.

Gimenez-Espin, J.A., Jiménez-Jiménez, D., Martínez-Costa, M., 2013. Organizational culture for total quality management. Total Qual. Manag. Bus. Excel. 24 (5-6), 678-692.

Fan, Y., Gencay, R., 1995. A consistent nonparametric test of symmetry in linear regression models. J. Am. Stat. Assoc. 90 (430), 551-557.

Glachant, M., Schucht, S., Bültmann, A., Wätzold, F., 2002. Companies' participation in EMAS: the influence of the public regulator. Bus. Strateg. Environ. 11, 254-266.

Gond, J.P., El Akremi, A., Swaen, V., Babu, N., 2017. The psychological microfoundations of corporate social responsibility: a person-centric systematic review. J. Organ. Behav. 38 (2), 225-246.

González-Benito, J., González-Benito, Ó., 2006. A review of determinant factors of environmental proactivity. Bus. Strat. Environ. 15 (2), 87-102.

Gouldson, A., Morton, A., Pollard, S.J.T., 2009. Better environmental regulation contributions from risk- based decision-making. Sci. Total Environ. 407, 5283-5288.

Greenwood, R., Díaz, A.M., Li, S.X., Lorente, J.C., 2010. The multiplicity of institutional logics and the heterogeneity of organizational responses. Organ. Sci. 21, 521-539.

Guoyou, Q., Saixing, Z., Xiaodong, L., Chiming, T., 2012. Role of internalization process in defining the relationship between ISO 14001 certification and corporate environmental performance. Corp. Soc. Responsib. Environ. Manag. 19, 129-140.

Hahn, T., Aragón-Correa, J.A., 2015. Toward Cognitive Plurality on Corporate Sustainability in Organizations: The Role of Organizational Factors.

Hahn, T., Figge, F., Pinkse, J., Preuss, L., 2010. Trade-offs in corporate sustainability: you can't have your cake and eat it. Bus. Strateg. Environ. 19 (4), 217-229.

Hahn, T., Preuss, L., Pinkse, J., Figge, F., 2014. Cognitive frames in corporate sustainability: managerial sensemaking with paradoxical and business case frames. Acad. Manag. Rev. 39 (4), 463-487.

Hemingway, C.A., 2005. Personal values as a catalyst for corporate social entrepreneurship. J. Bus. Ethic. 60 (3), 233-249.

Heras-Saizarbitoria, I., 2011. Internalization of ISO 9000: an exploratory study. Ind. Manag. Data Syst. 111 (8), 1214-1237.

Heras-Saizarbitoria, I., Arana Landín, G., Molina-Azorín, J.F., 2011. Do drivers matter for the benefits of ISO 14001? Int. J. Oper. Prod. Manag. 31 (2), 192-216.

Heras-Saizarbitoria, I., Arana, G., Boiral, O., 2015. Outcomes of Environmental Management Systems: the Role of Motivations and Firms' Characteristics. Business Strategy and the Environmenthttps://doi.org/10.1002/bse.1884.

Heras-Saizarbitoria, I., Kouakou, D., Boiral, O., 2013. Shedding light on ISO 14001 certification audits. J. Clean. Prod. 51, 88-98.

Hockerts, K., 2015. A cognitive perspective on the business case for corporate sustainability. Bus. Strat. Environ. 24 (2), 102-122.

Hoffman, A.J., 2001. Linking organizational and field-level analyses: the diffusion of corporate environmental practice. Organ. Environ. 14 (2), 133-156.

Iatridis, K., Kesidou, E., 2018. What drives substantive versus symbolic implementation of ISO 14001 in a time of economic crisis? Insights from Greek manufacturing companies. J. Bus. Ethics 148 (4), 859-877.

Iraldo, F., Testa, F., Frey, M., 2009. Is an environmental management system able to influence environmental and com- petitive performance? The case of the eco-management and audit scheme (EMAS) in the European Union. J. Clean. Prod. 17, 1444-1452.

Jackson, S.E., Dutton, J.E., 1988. Discerning threats and opportunities. Admin. Sci. Q. 370-387.

Kennedy, P., 2003. A Guide to Econometrics, fifth ed. MIT Press, Cambridge, MA.

Khidir ElTayeb, T., Zailani, S., Jayaraman, K., 2010. The examination on the drivers for green purchasing adoption among EMS 14001 certified companies in Malaysia. J. Manuf. Technol. Manag. 21 (2), 206-225.

King, M.F., Bruner, G.C., 2000. Social desirability bias: a neglected aspect of validity testing. Psychol. Market. 17, 79-103.

Link, S., Naveh, E., 2006. Standardization and discretion: does the environmental standard ISO 14001 lead to performance benefits? IEEE Trans. Eng. Manag. 53, 508-519.

Martín-de Castro, G., Amores-Salvadó, J., Navas-López, J.E., Balarezo-Nuñez, R.M., 2017. Exploring the nature, antecedents and consequences of symbolic corporate environmental certification. J. Clean. Prod. 164, 664-675.

Merli, R., Preziosi, M., 2018. The EMAS impasse: Factors influencing Italian organizations to withdraw or renew the registration. J. Clean. Prod. 172, 4532-4543.

Morrow, D., Rondinelli, D., 2002. Adopting corporate environmental management systems: motivations and results of ISO 14001 and EMAS certification. Eur. Manag. J. 20 (2), 159-171.

Nair, A., Prajogo, D., 2009. Internalisation of ISO 9000 standards: the antecedent role of functionalist and institutionalist drivers and performance implications. Int. J. Prod. Res. 47 (16), 4545-4568.

Nawrocka, D., Parker, T., 2009. Finding the connection: environmental management systems and environmental performance. Journal ofCleaner Production 17, 601-607. Nawrocka, D., Brorson, T., Lindhqvist, T., 2009. ISO 14001 in environmental supply chain practices. J. Clean. Prod. 17 (16), 1435-1443.

Nee, G.Y., 2011. Determining factors for ISO14001 EMS implementation among SMEs in Malaysia: a resource based view. World Academy of Science, Engineering and Technology 59 (1).

Neugebauer, F., 2012. EMAS and ISO 14001 in the German industry e complements or substitutes? J. Clean. Prod. 37, 249e256.

Nunnally, J.C., 1978. Psychometric Theory. McGraw-Hill, New York.

Perez-Batres, L.A., Doh, J.P., Miller, V.V., Pisani, M.J., 2012. Stakeholder pressures as determinants of CSR strategic choice: why do firms choose symbolic versus substantive self-regulatory codes of conduct? J. Bus. Ethics 110 (2), 157-172.

Petrocelli, J.V., 2003. Hierarchical multiple regression in counseling research: Common problems and possible remedies. Measure. Eval. Counsel. Develop. 36 (1), 9-22.

Podsakoff, P.M., MacKenzie, S.B., Lee, J.Y., Podsakoff, N.P., 2003. Common method biases in behavioral research: A critical review of the literature and recommended remedies. J. Appl. Psychol. 88 (5), 879.

Poltronieri, C.F., Ganga, G.M.D., Gerolamo, M.C., 2019. Maturity in management system integration and its relationship with sustainable performance. J. Clean. Prod. 207, $236-247$.

Potrich, L., Cortimiglia, M.N., de Medeiros, J.F., 2019. A systematic literature review on firm-level proactive environmental management. J. Environ. Manag. 243, 273-286.

Qi, G., Zeng, S., Li, X., Tam, C., 2012. Role of internalization process in defining the relationship between ISO 14001 certification and corporate environmental performance. Corp. Soc. Responsib. Environ. Manag. 19 (3), 129-140.

Ramalho, E.A., Ramalho, J.J., Murteira, J.M., 2011. Alternative estimating and testing empirical strategies for fractional regression models. J. Econ. Surv. 25, 19-68.

Rashid, N., Shami, S., 2017. The moderating effect of eco product innovation on ISO 14001 EMS and sustainable development. Proceedings of Mechanical Engineering Research Day 2017 (2017), 262-264.

Salim, H.K., Padfield, R., Hansen, S.B., Mohamad, S.E., Yuzir, A., Syayuti, K., Papargyropoulou, E., 2018. Global trends in environmental management system and ISO 14001 research. J. Clean. Prod. 170, 645-653.

Schuhwerk, M.E., Lefkoff-Hagius, R., 1995. Green or non-green? Does type of appeal matter when advertising a green product? J. Advert. 24 (2), 45-54.

Sharma, G., Good, D., 2013. The work of middle managers: sensemaking and sensegiving for creating positive social change. J. Appl. Behav. Sci. 49, 95-122.

Sharma, S., 2000. Managerial interpretations and organizational context as predictors of corporate choice of environmental strategy. Acad. Manag. J. 43 (4), 681-697.

Sharma, P., Sharma, S., 2011. Drivers of proactive environmental strategy in family firms. Bus. Ethics Q. 21 (2), 309-334.

Smith, W.K., Gonin, M., Besharov, M.L., 2013. Managing social-business tensions: a review and research agenda for social enterprise. Bus. Ethics Q. 23, 407-442.

Steensma, H.K., Tihanyi, L., Lyles, M.A., Dhanaraj, C., 2005. The evolv- ing value of foreign partnerships in transitioning economies. Acad. Manag. J. 48, 213-235.

Stern, P.C., Dietz, T., 1994. The value basis of environmental concern. J. Soc. Issues 50 (3), 65-84.

Stevens, P.A., Batty, W.J., Longhurst, P.J., Drew, G.H., 2012. A critical review of classification of organisations in relation to the voluntary implementation of environmental management systems. J. Environ. Manag. 113, 206-212.

Strauss, K., Lepoutre, J., Wood, G., 2017. Fifty shades of green: how microfoundations of sustainability dynamic capabilities vary across organizational contexts. J. Organ. Behav. 38 (9), 1338-1355.

Tambovceva, T., Geipele, I., 2011. Environmental management systems experience among Latvian construction companies. Technol. Econ. Dev. Econ. 17 (4), 595-610.

Testa, F., Boiral, O., Heras-Saizarbitoria, I., 2018a. Improving CSR performance by hard and soft means: the role of organizational citizenship behaviours and the internalization of CSR standards. Corp. Soc. Responsib. Environ. Manag. 25 (5), 853-865.

Testa, F., Boiral, O., Iraldo, F., 2018b. Internalization of environmental practices and institutional complexity: can stakeholders pressures encourage greenwashing? J. Bus. Ethics 147 (2), 287-307.

Testa, F., Heras-Saizarbitoria, I., Daddi, T., Boiral, O., Iraldo, F., 2016. Public regulatory relief and the adoption of environmental management systems: a European survey. J. Environ. Plan. Manag. 59 (12), 2231-2250.

Testa, F., Rizzi, F., Daddi, T., Gusmerotti, N.M., Frey, M., Iraldo, F., 2014. EMAS and ISO 14001: the differences in effectively improving environmental performance. J. Clean. Prod. 68, 165-173.

Tourangeau, R., Yan, T., 2007. Sensitive questions in surveys. Psychol. Bull. 133, 859-883.

Van der Byl, C.A., Slawinski, N., 2015. Embracing tensions in corporate sustainability: a review of research from win-wins and trade-offs to paradoxes and beyond. Organ. Environ. 28 (1), 54-79.

Wijen, F., 2014. Means versus ends in opaque institutional fields: trading off compliance and achievement in sustainability standard adoption. Acad. Manag. Rev. 39 (3), $302-323$.

Wong, E.M., Ormiston, M.E., Tetlock, P.E., 2011. The effects of top management team integrative complexity and decentralized decision making on corporate social performance. Acad. Manag. J. 54, 1207-1228.

Yin, H., Schmeidler, P.J., 2009. Why do standardized ISO 14001 environmental management systems lead to heterogeneous environmental outcomes? Bus. Strateg. Environ. 18 (7), 469-486.

Zobel, T., 2016a. The impact of ISO 14001 on corporate environmental performance: a study of Swedish manufacturing firms. J. Environ. Plan. Manag. 59 (4), 587-606.

Zobel, T., 2016b. The impact of ISO 14001 on corporate environmental performance: a study of Swedish manufacturing firms. J. Environ. Plan. Manag. 59 (4), 587-606. 